\title{
Development of intercity work mode choice model for Saudi Arabia
}

\author{
H. M. Al-Ahmadi \\ Civil Engineering Department, \\ King Fahd University of Petroleum and Minerals, Saudi Arabia
}

\begin{abstract}
Several mode choice models are developed all over the world to predict the tripmaker choice of using a specific mode among set of transportation modes. This modeling is quite important from a planning point of view since the transportation systems usually receive huge investment. However, the development of new models for a certain locality or even modifying some to suit this locality needs a lot of funds that sometimes are not easy to provide.

In Saudi Arabia, there are some characteristics of intercity tripmakers that differ from those of other tripmakers in other countries. These characteristics include cultural, socioeconomic, safety, and religious parameters.

In this study, the main purpose was to develop an intercity work mode choice model for Saudi Arabia. The required data was collected from all major cities throughout Saudi Arabia. A behavioral work mode-choice model was successfully built and validated with an independent sample for work trips. This model indicated that in-vehicle travel time, out-of-pocket cost, number of family members traveling together, monthly household income, travel distance, nationality of the traveler, and number of cars owned by the family played a role in decisions related to intercity mode-choices. This model will help government and public transportation agencies and private carriers to make decisions, and to prevent under-design or over-design of the facilities.
\end{abstract}

Keywords: work mode choice model, Saudi Arabia, travel demand models.

\section{Introduction}

Saudi Arabia is one of the rich developing countries. Its wealth comes primarily from oil revenues. The discovery of oil in Saudi Arabia changed the Kingdom of 
Saudi Arabia from a pre-industrial country to a modern industrial country. This brisk change placed a burden on all public utilities and facilities, especially the transportation system.

Understanding the behavior of tripmakers in selecting a travel mode is necessary for public transportation agencies or private carriers to make managerial decisions, and to prevent under or over-design. For instance, underestimation of future travel demand may lead to congestion, delay, high accident rates on many major roads, and excessive stand-by passengers at major airport terminals. These problems may waste valuable manpower and time, and may impede the economic development of the Kingdom. At the other extreme, if future travel demand is overestimated, too much capital will be tied up in transportation facilities and not used for other more needed aspects of development.

An intercity model must exist to predict the future modal split. The results of this study will provide the transportation agencies with a tool to maximize their revenue and better allocate their resources.

\section{Behavior of the intercity tripmaker in Saudi Arabia}

The first step in any engineering work is planning. In transportation, planning is especially important because transportation systems are among the most expensive investments to build or modify. The investment in transportation improvements should be based on the understanding of future demand. To achieve this, an understanding of tripmaker behavior is essential.

Understanding the behavior of the tripmaker will provide the model builder with the most likely variables for inclusion in the model. The definition of a tripmaker in this research is a person traveling between cities alone or with family. The following paragraphs discuss the characteristics of Saudi behavior when a person makes an intercity trip. These characteristics may not be applicable to Western culture.

In Saudi Arabia, the percentage of females traveling alone from one city to another is very low [1]. This is because the Islamic religion forbids women to travel alone. In addition, women are not allowed to drive in Saudi Arabia. They may use an airplane to travel alone, but only under special circumstances, and relatives must meet them at the airport.

Another factor affecting the tripmaker in choosing an intercity mode is the weather. In Saudi Arabia the weather, especially in summer, does not encourage the tripmaker to use ground transportation.

Saudi tripmakers are very concerned with safety, because the risk of becoming involved in a car accident is very high [2]. This perception of risk may cause the tripmaker to hesitate to drive his car or use ground transportation for an intercity trip.

Another characteristic of Saudi tripmakers is that they prefer, for non-business trips, to travel as families since the average family size is around six [3]. 


\section{Disaggregate modeling}

The disaggregate approach was the second generation in model building after the aggregate approach in mode choice modeling [4]. The development of disaggregate models provided a more effective tool for predicting an individual's behavior in selecting one mode from among different modes available. The decrease in explanatory power of the aggregate models due to data aggregation was avoided with the disaggregate models [5].

The development of disaggregate models was extensively documented [6-13] and is widely used in urban travel analysis.

The use of disaggregate models is supported by their representation of the individual tripmaker's decision, data efficiency, and superior estimation results. Most disaggregate models are based on the theory of "utility maximization." They assume that a person makes a particular choice from a set of different alternatives depending on the maximum benefit he receives. For example, a person may wish to minimize travel time and cost of the trip, and maximize comfort and convenience in selecting a mode from the available modes.

The primary model form for intercity mode choice utilizing disaggregates data is in a probabilistic form, as seen in the following example:

$$
\mathrm{P}_{\mathrm{k}}^{\mathrm{i}}=\frac{e^{\mathrm{V}_{\mathrm{ki}}}}{\sum_{j} e^{\mathrm{V}_{\mathrm{ki}}}}
$$

where:

$\mathrm{P}_{\mathrm{k}}^{\mathrm{i}} \quad$ = probability of tripmaker $\mathrm{i}$ choosing mode $\mathrm{k}$ out of $\mathrm{j}$ alternatives

$\mathrm{V}_{\mathrm{ki}} \quad=$ the utility of alternative mode $\mathrm{k}$ to trip maker $\mathrm{i}=\left(\mathrm{X}_{\mathrm{k}}, \mathrm{S}_{\mathrm{i}}\right)$

$\mathrm{X}_{\mathrm{k}} \quad=\mathrm{a}$ row vector of characteristics of alternative mode $\mathrm{k}$

$\mathrm{S}_{\mathrm{i}} \quad=$ a row vector of socioeconomic characteristics of a tripmaker $\mathrm{i}$

From this equation, it is clear that the probability of a tripmaker choosing a particular mode is a function of the characteristics of the tripmaker; such as, income, age, and sex and of the characteristics of the mode relative to alternative modes.

\section{Data collection and analysis}

\subsection{Data required categories}

Based on the literature, the data needed for specifying, calibrating and testing transferability consist of three categories: socioeconomic variables, level-ofservice or supply variables, and data regarding the trip. Some of these variables are qualitative and others are quantitative. In model calibration it cannot be predetermined which variables best explain the tripmaker's behavior unless the impact of the other variables is tested in the preliminary modeling stage. The following variables have been collected and used to determine the best fit model for each corridor under study. 


\subsection{Level-of-service variables}

For the level-of-service variables, which may influence the tripmaker's choice, the following variables have been collected such as: in-vehicle travel time, access time, egress time, waiting time and total travel cost. Travel cost is the total cost perceived by the tripmaker, such as airplane fare or fuel for the car user. This is mainly out-of-pocket cost. Perceived cost has been found to be more important than actual cost in mode choice decision-making from the traveler's point of view [8]. Trip cost has been estimated in Saudi Riyals. This total cost for travel consists of two parts. One is in-vehicle cost, which includes fare paid for the major carriers, e.g., airplane, and the perceived operation cost for a private car. The other component is the out-of-vehicle cost, which includes costs such as access, egress, and parking costs.

\subsection{Socioeconomic variables}

Another category of data collected consisted of socioeconomic variables. Socioeconomic variables collected such as: income, car ownership, license, number of family members traveling, age and nationality.

\subsection{Trip variables}

Data regarding the trip were collected and are summarized as follows:

1. Trip purpose. The distinction among trip purposes is an important step in mode choice analysis because different tripmaker behaviors are expected in selecting a mode for different trip purposes [8].

2. Duration of stay. The length of time a tripmaker is planning to stay at the destination city has been collected. The categories for this variable are one day, 2-7 days, and more than 7 days.

3. Distance. The distance between the origin and the destination of the trip.

\section{Data collection and analysis}

A specially designed questionnaire form was distributed for each mode under consideration. Because many tripmakers in Saudi Arabia are from different countries, and the most prevalent languages among tripmakers are Arabic and English, the questionnaire forms were written in both Arabic and English. These forms were distributed at the airport terminal, bus terminal, and train station for tripmakers traveling in the corridors under study. Questionnaires were distributed on-board while the subjects waited for the departure. The completed questionnaires were collected at the destination of each trip.

Tripmakers traveling by car were interviewed at the gas stations located midway between the cities under study. In addition, one-hundred questionnaire forms were placed at the gas stations. However, none of these questionnaires were returned, even though the recipients were asked to complete the questionnaire and return it by repaid mail. 
This questionnaire included a wide range of variables characterizing the trip (by mode, trip purpose, origin destination, duration, etc.), the service characteristics of both the chosen mode and perceived characteristics of other available but unchosen modes (travel time, cost, frequency, etc.), and the tripmaker's characteristics (age, income, occupation, etc.). Moreover, the questionnaires were coded by the name of the four different modes under study: airplane, private car, and bus.

Those respondents who said that they will "never consider using" other modes other then the chosen one are assumed to be "captive" to the chosen mode. Captives are excluded from the calibration data set as they do not make a choice.

The data cleaned of missing data and of captive riders were separated for the work trip categories. Approximately $1 / 3$ of these data sets (272) were reserved for model validation and $2 / 3$ was used (491) for model calibration. Selection for these was randomized.

\subsection{Model specification}

Different specifications for the model have been evaluated to determine which specification best replicates the data for different trip purposes. These specifications include the variables that have been found in the literature review to influence the tripmaker choice [such as total cost (TOTALC), egress travel time (EGTM), access travel time (ACTM), household income (HHIN), total travel time.

(TOTAT), out-of-vehicle travel time (OVTT), distance (DIST), in-vehicle travel time (IVTT), and waiting time (WTTM)]. Composite variables such as TOTALC/HHINC and OVTT/DIST are used to modify the impact of the pure level-of-service variables TOTALC and OVTT. It is hypothesized that tripmakers with different levels of income perceive travel cost differently. Similarly, out-of-vehicle time is hypothesized as becoming less important as the length of the trip increases.

Different model specifications were tested. Each model estimate is based on a different model utility function. Model specifications were formulated based on prior experience in intercity mode choice modeling, and the impact of introducing additional explanatory variables.

Some of the models tested exhibited poor statistical goodness-of-fit and/or counter-intuitive signs and were rejected. For example, some models produced a very good fit but it has a counter-intuitive sign in the variable total travel time. In summary, the logic employed to move from one specification to another can be described as follows:

- $\quad$ variables with insignificant coefficients were dropped;

- variables that had the "wrong" signs were dropped;

- $\quad$ variables that were related to level-of-service (i.e., those that might be considered supply variables) were considered in both straightforward ways (e.g., the cost variable was added) and in ratio forms (e.g., cost divided by income); 
- $\quad$ sets of variables with high correlations were considered and selected variables were dropped;

- different versions of several variables with "wrong" signs were considered (e.g., out-of-vehicle time was examined as a mode-specific variable); and finally,

- Several intuitively important variables which had been dropped were reconsidered (in the original form and/or, for example, in modespecific form).

Of all the model specifications tested, the most satisfactory models for work trip purpose are presented in Table 1.

Table 1: $\quad$ Work mode-choice model.

\begin{tabular}{|c|c|c|c|}
\hline $\begin{array}{l}\text { INDEP } \\
\text { VARIABLE }\end{array}$ & ESTIMATE & T-STAT & STD.ERROR \\
\hline 1ASC-AIR & 0.879166 & 1.93714 & 0.453847 \\
\hline 2ASC-BUS & 1.61886 & 4.83754 & 0.334645 \\
\hline 3TIMEI & $-0.826134 \mathrm{E}-01$ & -2.37859 & $0.347321 \mathrm{E}-01$ \\
\hline 4COSTT & $-0.151494 \mathrm{E}-02$ & -2.42632 & $0.624378 \mathrm{E}-03$ \\
\hline 5DFMLYC & 1.45624 & 4.53257 & 0.321284 \\
\hline 6DNATIONB & 0.612579 & 2.04689 & 0.299272 \\
\hline 7HHINA & 0.279496 & 4.30456 & $0.649301 \mathrm{E}-01$ \\
\hline 8DISTC & 1.03243 & 3.20249 & 0.322385 \\
\hline $\begin{array}{l}\text { LOG LIKELIHOO } \\
\text { RHO SQUARED }\end{array}$ & $\begin{array}{l}D=-278.957 \\
=0.314502\end{array}$ & $\begin{array}{l}\text { LOG LIK } \\
\text { RHO-BA }\end{array}$ & $\begin{array}{l}\text { HOOD }(0)=-406.941 \\
\text { UARED }=0.307989\end{array}$ \\
\hline \multicolumn{4}{|l|}{ Where: } \\
\hline $\begin{array}{l}\text { ASC-AIR } \\
\text { ASC-BUS } \\
\text { TIMEI } \\
\text { COSTT } \\
\text { DFMLYC } \\
\text { HHINA } \\
\text { DISTC } \\
\text { DNATIONB }\end{array}$ & $\begin{array}{l}=\text { Mode-speci } \\
=\text { Mode-speci } \\
=\text { In-Vehicle } \\
=\text { Out-of-pocl } \\
=\text { Dummy fan } \\
=\text { Monthly ho } \\
=\text { Dummy for } \\
=\text { Dummy for }\end{array}$ & $\begin{array}{l}\text { c constant } \\
\text { c constant } \\
\text { me in hour } \\
\text { t total cost } \\
\text { ly for car } \\
\text { sehold inco } \\
\text { listance for } \\
\text { lationality }\end{array}$ & $\begin{array}{l}\text { or air } \\
\text { for bus }\end{array}$ \\
\hline
\end{tabular}

The coefficients of the parameters in the model have the expected signs. The coefficients of in-vehicle travel time and total out-of-pocket cost are negative, as expected, while all the dummy variables are positive, as expected.

It is clear from the t-stat (t-statistic) values for the variables in Table 1 that the null hypothesis that the true value of each coefficient is zero can be rejected at least at the 0.05 significance levels. 
The goodness-of-fit measure rho-square (p2) is 0.314 . The p2 statistics represent a very good fit and the adjusted likelihood ratio index (rho-squared bar) is 0.308 .

The null hypothesis that all the parameters are zero $(\mathrm{B} 1=\mathrm{B} 2=\mathrm{B} 3 \ldots \mathrm{Bk}=0)$ is tested by the log-likelihood ratio test $(-2(\mathrm{~L}(0)-\mathrm{L}(\mathrm{B})$, which is $\mathrm{X} 2$ (chi-square) test and has a degree of freedom equal to the number of model parameters [13]. The critical X2 value with degrees of freedom equal to the model parameters, and a 0.05 level of significance (X2 $0.05,8)$, is 15.51 . In other words, the null hypothesis that all the parameters are jointly zero is rejected at the $95 \%$ level. Moreover, the null hypothesis that all the coefficients, except the mode-specific constants, are zero is rejected also at the $95 \%$ level.

\subsection{Model validation}

Model validation was conducted by using the calibrated model to predict modelsplit for data other than that used for model calibration. Two hundred seventytwo observations for the work trips not used in model calibration were used to test model validity.

A test of reasonableness validation process was used first in model calibration phase. This process depends on the reasonableness of the model in terms of the expected coefficient signs, and the reasonableness of the parameters.

Validation tests were conducted by the Likelihood Ratio Test statistic (LRTS). This test is asymptotically distributed as X2 (chi-squared) with degrees of freedom equal to the number of model parameters (13).

The results of the validation tests shows that there is no significant difference between the observed behavior and the predicted at a significance level of 0.05

\section{Conclusions and recommendations}

A general approach to calibrate intercity disaggregate mode choice models in Saudi Arabia was presented. Three specific models were developed for Saudi Arabia. The specification of model utility will help in further study to concentrate in which data is needed is necessary. The main conclusions of the research are listed below.

1. Behavioral work mode-choice model were successfully built and validated. This model indicated that in-vehicle travel time, out-of-pocket cost, number of family members traveling together, monthly household income, travel distance and nationality of the traveler played a role in decisions related to intercity mode-choices. The co-efficient estimates all had the expected signs, were statistically significant (at least at 5\% level) and had satisfactory explanatory power (as revealed by the relatively high values of the $\mathrm{p} 2$ values). This model will be helpful in travel demand analysis for Saudi Airlines, Ministry of Communication, bus and train operators.

Further research recommendations in this area are listed below:

1. The phenomenon of mode-captivity, although investigated to some extent here, deserves a more extensive study. Problems related to captivity includes, 
first definition of captivity, its effects on model building and predictions. This phenomenon is similar to "brand loyalty" in marketing analysis and can perhaps be better analyzed through "time-series" rather than "cross-sectional" data. People are most likely to be affected by their past experiences in intercity travel. In future studies, at least an effort should be made to ask questions related to past trips and try to analyze the effect of past choices on the present ones.

2. Another possible area of research involves "stated preferences" as opposed to using "revealed preferences" used in this research [8]. These methods allow the analyst to extract much more information from each respondent including data from a non-existing mode (such as train for various corridors in Saudi Arabia).

3. Finally, it is very important for the transport industry to cooperate with university researchers in developing and applying the current planning technology. With their support, research will become more productive and useful.

Other aspects of intercity passenger demand, such as traffic generation, distribution and assignment should be studied. Some of these can be analyzed simultaneously using abstract mode models [5].

\section{Acknowledgements}

The authors wish to acknowledge the Civil Engineering Department and the Research Institute of King Fahd University of Petroleum and Minerals for supporting this research.

\section{References}

[1] Al-Ahmadi, H.M., Ergün, G., Al-Senan, S.H. and Ratrout, N.T., "Development of a National Intercity Modal Split Model for Saudi Arabia," Final Report, King Abdulaziz City for Science and Technology, Riyadh, Saudi Arabia (September 1993).

[2] Riyadh Traffic Directorate Site: http://www.rt.gov.sa/english /accidents1.php, Riyadh, Saudi Arabia, 2005

[3] Ministry of Economy and Planning, Central Department of Statistics Site (CDS), http://www.planning.gov.sa/docs/DS2K23.htm, Riyadh, Saudi Arabia, 2000.

[4] Koppelman, F. S., G. Kuah, and M. Hirsh. Review of Intercity Passenger Travel Demand Modeling: Mid-60's to the Mid-80's. Department of Civil Engineering, Northwestern University, Draft copy. 1984.

[5] Kanafani, A. Transportation Demand Analysis. McGraw-Hill Book Company. New York. 1983.

[6] Watson, P. L. "Predictions of Intercity Model Choice from Disaggregate Behavioral and Stochastic Models. Highway Research Record 446. pp. 28-35 (1972). 
[7] Watson P. L. "Comparison of The Model Structure a Predictive power of Aggregate and Disaggregate Models of Intercity Mode Choice. Transportation Research Record 527. 1974. pp. 59-65.

[8] [8] Ben-Akiva, M.T., Morikawa and F. Shiroishi, "Analysis of the Reliability of Stated Preference Data in Estimating Mode Choice Models," Selected proc., 5th WCTR, Vol. 4, Yokohoma, Japan, pp. 263-277, 1989.

[9] Algarad, Saad, N., "Disaggregate Mode Choice Modeling for Intercity Non-Business Travellers in the Saudi Arabia-Bahrain Corridor," Unpublished Ph.D. dissertation, Indiana University, Bloomington, IN, 1993.

[10] McFadden, D. The theory and Practice of Disaggregate Demand Forecasting for Various Modes of Urban Transportation. Emerging Transportation Planning Methods. 1978.

[11] Ben-Akiva M. Structure of Passenger Travel Demand Models. Ph.D. Dissertation. Department of Civil Engineering. MIT. Cambridge, Mass, 1973.

[12] Ortuzar, J, and L Willmusen" Modelling Transport” John Wiley \& Sons Press, third edition, 2001.

[13] Ben-Akiva, M., and S.R. Lerman. Discrete Choice Analysis. MIT, Cambridge, Mass., 1985. 